\title{
Parents as victims of rebellious children, and children who suffer from Tourette Syndrome
}

\author{
Ronelle Pretorius \\ Dept. of Criminology \\ University of Pretoria \\ PRETORIA
}

\begin{abstract}
Abused parents are the forgotten victims of family violence. This paper reports on the victimisation of 50 parents who are members of a lay support group, "Parents of Rebellious Children" (PORCH). Although it was not the aim of this study to investigate the role that TS could possibly play, it was a serendipity finding that TS may be a contributing factor in the rebelliousness exhibited by some children. These parents did not only experience severe verbal and physical abuse but also suffered serious damage to property at the hands of their violent children. They were often blamed if they spoke of their plight and received little moral support. Abused parents need to be recognized and treated as victims of violence. Eleven rebellious children who were treated for TS with psychotropic drugs, showed dramatic behavioural changes and the implications of such treatment are also indicated.
\end{abstract}

\section{Introduction}

Wife and child abuse have received much attention over the past years (Colvin, 1982; Eekelaar \& Katz, 1978; Garbarino \& Garbarino, 1982; Pagelow, 1981; Straus et al., 1980). However, another category of victimisation, namely the emotional and/or physical abuse of parents by their children, has been largely neglected or ignored. A possible reason for this can be ascribed to the JudeoChristian viewpoint that requires children to respect their parents and prohibits them from cursing, provoking, or physically assaulting them. Parents whose children break this rule may find it difficult to talk about their experiences. They may remain silent because they are ashamed of what is happening or fear that they will be regarded as poor disciplinarians, lacking the ability to rear their children according to the required norms (Pretorius, 1992:9). They may also feel that the disclosure of the fact that their children are victimising them will be regarded as a disgrace. 
Whereas rebellious children, and the problems caused by delinquency receive adequate attention from psychologists, social workers and criminologists, the parents, as victims of abuse, are ignored (Borland, 1976). These parents usually suffer in silence. Academics and researchers working with children who have behavioural problems do not always realise that the parents experience anxiety, guilt feelings, suffer emotionally, feel hopeless and powerless, and have a need for empathy.

The only type of parent victimisation that has received attention from researchers, is granny bashing (Finkelhor, 1983). Regarding the lack of research on parent bashing, Straus et al. (1980:119) say "perhaps one does not hear about it (and researchers do not study it) because of the need to preserve the myth that all children love and respect their parents". In addition as Walklate (1989:69) points out, the notion of "childhood innocence" is very strong in modern society. Sears and his associates (in Straus et al., 1980:119) was possibly the first researcher who briefly referred to parental battering by teenagers in their 1959 publication, Patterns of Child Rearing. These researchers found that one of the reasons parents put forward for beating a child was that the child had assaulted them. In a national survey on family violence conducted in the USA Straus et al. (1980) found that approximately $18 \%$ of the children in the sample assaulted their parents during the year the survey was conducted. Furthermore it appeared that the frequency with which parents assaulted their children was directly related to the frequency with which the children assaulted their parents.

In a newspaper article "Testy kids drive parents to drink" (Weekend Post, 199009-01) it became evident that the excessive drinking of some parents could be attributed to the disruptive behaviour of their children. In this regard the journalist states that "while we usually think of parents as influencers of children, children can affect parents as well. And the outcome is not always favourable".

Since a dearth of information regarding parental abuse by their rebellious children apparently exists, a study was undertaken to determine parents' experience of verbal and physical abuse. Although it was not the aim of this study to investigate the role that TS could possibly play, it was a serendipity finding that TS may be a contributing factor in the rebelliousness exhibited by some children. When medication is administered it may result in a dramatic improvement in the behaviour of rebellious children suffering from TS.

\section{Research procedure and background of the study}

The data for this study was obtained through a lay support group, Parents of Rebellious Children (PORCH) and the Department of Human Genetics and Developmental Biology of the Faculty of Medicine at the University of Pretoria. 
PORCH is a selfhelp, support group (Borman, 1982) for parents whose children exhibit severe behavioural problems. The aims of PORCH is to offer a forum to parents where they can discuss the problems they experience in coping with their rebellious children, and to give moral support to each other.

The Department of Human Genetics and Developmental Biology of the University of Pretoria is currently involved in research on TS as well as the behavioural problems associated with it. Prof. George Gericke, Head of the Department of Human Genetics and Developmental Biology is also Head of the TS Clinic of the above-mentioned department. He is regularly confronted by parents with requests for assistance in the controlling of the rebelliousness and behavioural problems shown by their children suffering from TS, and he invited the author to join their research team as from January 1991. After attending a number of interviews conducted at the TS Clinic, it became apparent that the complaints of some of the parents of children with TS corresponded to those of parents belonging to PORCH. This realisation lead to the inclusion of a selected number of parents who attended the PORCH group and whose children were diagnosed as TS patients.

A total of 50 parents were included in the sample, eleven of these parents' $(22 \%)$ children were diagnosed as TS patients. They completed a questionnaire which is based on the Conflict Tactic Scale of Straus et al. (1980:253-256). This questionnaire inter alia provides information on the following:

- The extent of the children's aggression and violence as experienced by the parents.

- How the rebellious behaviour of children influences the parents' sleeping patterns, their health, and relationships with other family members.

- The extent to which parents are blamed for their children's behaviour.

- Feelings of failure, self-blame and hopelessness experienced by parents.

- Whether the parents require support and assistance for the problems they have with their children and how others respond to their need for support and assistance.

These questionnaires were completed at a PORCH meeting under the supervision of the researcher. Where necessary, further interviews were conducted by the author herself to get more information on aspects she rendered necessary. This information was verified at the TS Clinic by studying the files of the respondents. 


\section{Results}

\subsection{The questionnaire completed by parents belonging to $\mathrm{PORCH}$}

An analysis of the data shows that parents who become members of PORCH regard themselves as victims of their children's rebellious behaviour. They join this support group because all attempts to control their children's behaviour by means of educational, psychological, psychiatric, social worker and even police intervention have failed to provide solutions. As members of PORCH they hope to at least receive moral and emotional support from other group members who are equally distressed by the unruly behaviour of their children. Muller (1987:36) states that "(selfhelp groups) are formed ... for mutual assistance in satisfying a common need, overcoming a common handicap or life-disrupting problem, and bringing about desired social and/or personal change".

\subsubsection{Behavioural problems reported by parents}

Behavioural problems reported by parents about their children take various forms, and the seriousness of these are highlighted by the following: $40 \%$ of these children had at one stage or another clashed with the police; $34 \%$ had been referred to an institution for treatment or rehabilitation; and $88 \%$ did not only achieve poorly at school but their parents were approached by teachers with complaints about behavioural problems.

\subsubsection{Reasoning}

The desperate position of parents is clearly demonstrated in the way in which these children reason. According to the data obtained from the respondents all of these rebellious children lack the ability to calmly discuss and reason about a problem. All the parents reported that a difference of opinion is never settled in an acceptable manner, the general patten being that any small problem develops into a heated argument. A further characteristic of these children is their refusal to take no for an answer. A typical example is a child who used the family car on numerous occasions without permission and has been involved in an accident, but does not want to understand why he is not permitted to use the car whenever he so wishes. Reports of vehicles being used once or more without permission occurred in $48 \%$ of the sample.

Arguments due to parents' refusal to continue to provide money, or allowing children to go out or to stay out late, usually result in aggression and conflict. The outcome of these conflicts is usually the child storming out of the house and slamming the doors. Parents experience this behaviour as an unwillingness of the child to listen to reason, an ignoring of the problem or that the context within 
which the discussion takes place is disregarded. This contributes to parents' feeling that they are not getting through to the child, and this consequently leads to feelings of frustration and desperation.

\subsubsection{Verbal abuse}

The verbal abuse of parents is extensive; only nine (18\%) respondents reported that they have never been sworn at by their children. In addition to using the most vile language, some of the parents indicated that the cursing usually ends with the child making an obscene sign before storming out of the room.

Parents indicated that they experience cursing by the child as being traumatic They felt that they have failed as parents, and that the child's behaviour is a reflection of a hopeless parent-child relationship. The swearing of the child is feared because they are afraid that the other children in the family or even the neighbours may overhear.

Only one parent in the sample ( $2 \%)$ indicated that her child never purposely said anything to hurt her. The others, however, reported that their children constantly confronted them with the shortcomings and mistakes they had made, as well as with their inability to provide enough money and grant whatever the child wished for. The majority of parents also indicated that they found it traumatic when the child tried to humiliate them in the presence of other children or their spouses.

\subsubsection{Aggression}

Aggression displayed towards parents manifested in many forms: $54 \%$ of the parents reported having been threatened more than once that they would be beaten up or that an object would be thrown at them; $24 \%$ experienced at least once that an object such as a shoe, cup, book or toy was thrown at them. One of the mothers reported that her 16 year old son in one instance threw his plate of food at her because she had served vegetables in addition to the meat and potatoes he preferred.

Various parents (44\%) reported that they had been subjected to physical violence at least once. The assaultive behaviour involved being kicked at or physically shaken during an argument. Furthermore parents reported that they were injured $(26 \%)$, or that furniture was broken during such encounters $(20 \%)$. A number of parents $(20 \%)$ indicated that this type of violence followed an incident in which one of the parents had attempted or threatened to slap the child and the child then retaliated by hitting back. Twenty four percent of the parents indicated that they had been beaten more than once with the fist, 16\% had been threatened with a knife or fire-arm, while three parents $(6 \%)$ were stabbed with a knife or a pair of scissors. Although these assaults were traumatic, serious injury was avoided. 
Despite the trauma of being assaulted by one's own child, only $14 \%$ of the subjects believed that the assaults were of a serious nature. The seriousness of the assaults was judged in terms of the nature of the injury, such as a bruise due to being beaten with the fist, a cracked lip on account of a slap, or lesions sustained during a fall after having been pushed around. The three parents who were assaulted with sharp instruments described these incidents as serious because of the possible injuries that could have been sustained in such attacks.

\subsubsection{Effect on the parents}

An important question that arises is how this rebellious behaviour of a child affects the parents. In this regard $82 \%$ of the respondents stated that they lay awake at night worrying about their child. They were especially concerned about the child's future, whether he will be able to pass his grades at school and his ability to prepare himself for an occupation. Seventy percent attributed a poor appetite to the child's behaviour while $48 \%$ believed that their ability to concentrate at work was seriously impaired. Some parents $(40 \%)$ believed that this impairment was so serious that their productivity was affected. Twenty nine of the respondents $(58 \%)$ indicated that the behaviour of the rebellious child had a negative effect on their relationship with their spouse, while $70 \%$ believed that it had a detrimental effect on their relationship with the other children in the family. The negative effect that the rebellious child has on the family is further demonstrated by the fact that $82 \%$ of the parents reported that the total household is disrupted in some way or another and that they were powerless to do anything about it.

\subsubsection{Blaming of the parents}

According to the respondents they are more frequently blamed for their children's behaviour by relatives than by non-family members. Being blamed by their own parents as well as brothers and sisters was reported by $70 \%$ of the respondents. Friends (46\%) were the next largest group that blamed them for either being too strict or being too slack in disciplining the child.

In addition to family and friends some of the parents (46\%) blamed one another for the child's unruly behaviour. This was based on perceptions that one of the parents either favoured the child by ignoring his unacceptable behaviour or by nagging so much that it contributed towards the problem.

Thirty six percent of the respondents reported that teachers blamed them in a subtle way for the child's bad behaviour at school, as well as for his poor academic achievement. A further $10 \%$ indicated that neighbours gave them advice regarding child rearing and made them feel responsible for the behaviour of the child. 
From the above it appears that various groups of people blame the parents directly or indirectly for their children's behaviour. In the questionnaires all the parents emphasized that being blamed for their children's behaviour frequently made them feel that they have failed as parents. These subtle accusations hurted and insulted them because they felt that it is based on misconceptions and deductions that cannot be substantiated. These misconceptions contribute towards them becoming victims of the child's behaviour over which they have little or no control.

\subsubsection{Need for support}

All the parents at one time or another have approached a professional person for help. Fifty eight percent of the respondents consulted teachers, while $74 \%$ consulted social workers, psychologists and psychiatrists. Although $64 \%$ indicated that the professionals they approached were helpful, it needs to be stressed that the focus was on the child and not on the problems the parents had to cope with As a rule consultations focused on the child's behavioural problems and not on the pain and suffering these caused the parents.

In addition to consulting professional people, $64 \%$ of the parents discussed their problems with friends, while $72 \%$ turned to relatives for help. Although the majority of parents found it easier to talk to friends and relatives about their fears, pain and general emotional state, these individuals were unable to assist. Usually they gave advice which was of little help, or they advised parents to change their methods of child rearing. This, as well as subtle references to the parents' shortcomings, made them feel that they were, if not fully, then at least partially, to blame for the dilemma. In this regard $88 \%$ reported that they felt that they had failed as parents, and $58 \%$ believed that they were somehow responsible for their child's behaviour. This indicates that self-blame is a feeling that is regularly experienced by these parents.

Parents are of the opinion that society offers very little support: $82 \%$ indicated that in reality there was no available help for parents such as them, and that the only people who could understand their dilemma, were those parents in a similar situation. Because of this, $70 \%$ indicated that they often felt so desperate that they considered irrational behaviour such as leaving home or turning the rebellious child out into the street. 


\subsection{Relationship between rebellious behaviour and Tourette Syndrome}

\subsubsection{Tourette Syndrome}

TS is a genetic disorder which manifests as a chemical imbalance in the synapse or space between neurons or nerve cells in the brain. This hereditary disorder is characterised by suppressible motor and vocal tics that occur almost daily. The Diagnostic and Statistical Manual of Mental Disorders (DSM-III-R) defines a tic as "an involuntary, sudden, rapid, recurrent, nonrhythmic, stereotyped motor movement or vocalization. It is experienced as irresistible, but can be suppressed for various lengths of time" (quoted in Comings, 1990:12). Compulsive swearing (coprolalia) is probably the most dramatic and publicised symptom of TS, but just as important are very common motor tics like eyeblinking, licking of lips, facial grimacing and the shrugging or jerking contractions of any muscle, such as that of the neck and shoulder.

However, what is of importance for this paper is that a wide range of behavioural problems in children have been found to be associated with TS. Comings (1990) reports extensively on this phenomenon in his book Tourette Syndrome and Human Behavior. Research done by Chase, Friedhoff and Cohen (1992) as well as by Kurlan (1993) convinces the author that TS may, at least to some extent, play a role in violent behaviour.

\subsubsection{Tourette Syndrome and rebellious children}

The parents of eleven children with TS who were interviewed for this study, complained of behavioural problems which included defiance of authority, aggressiveness and violence, lying, stealing, destructiveness, disobedience and poor interpersonal relationships. These corresponded exactly with the behavioural problems that parents of rebellious children complained about.

The eleven children diagnosed as suffering from TS were treated with psychotropic drugs for their motor and vocal tics. In addition to an improvement of the tics it also became evident that a dramatic change in these children's behaviour had occurred within three weeks after starting to take these drugs (Clonidine or Pimozide). Feedback from the parents indicated that the children were no longer as impatient as before, impulsiveness and excitability had declined and in general their behaviour had become socially more acceptable. The following case illustrates this point:

One of the patients with an 18 year old boy, had before being given a psychotropic drug (Pimozide) for TS, licked his lips compulsively to such an extent that 
Ronelle Pretorius

he had developed chronic ulcers around his mouth. Furthermore he had a history . of alcohol abuse, promiscuity, stealing and selling his parents' property, violent assaults on his mother and behavioural problems at school. After approximately three weeks of taking Pimozide he stopped licking his lips, and his mother reported that he had calmed down and behaved in a more acceptable manner. In addition to this his interest in school work became evident. He also became willing to co-operate in a psychotherapy programme. Indications were that he would be able to adjust to a normal and acceptable lifestyle, and that interaction with his parents as well as with other individuals were improving.

\section{Conclusions}

Parental victimisation by children is a phenomenon that should not be disregarded. It is a reality that parents are being blamed for their children's misbehaviour while they are at their wits' end in handling these children. Although these parents desperately need help they feel that they had no one to relate their feelings of pain and powerlessness to. If their desperation for emotional and moral support is considered, it has become essential that all psychologists and other professionals dealing with rebellious children should become more aware of the fact that the mental health of these parents should be an integral part of any therapeutic programme or intervention.

Although it cannot be denied that a host of social and psychological factors may be responsible for rebellious behaviour in children, it is also essential that these children should be evaluated for TS. If a positive diagnosis is made, their behavioural problems can effectively be treated with psychotropic drugs in combination with other therapeutic techniques, such as psychotherapy and behaviour therapy. Therapists should always bear in mind that although children with TS have a good prognosis, if they receive pharmacotherapy they, as well as their parents, may have developed certain behavioural patterns due to poor communication. With the unlearning of these behavioural patterns it is necessary to support the children, as well as their parents, in developing better communication and interpersonal skills.

Finally it is imperative that cognisance should be taken of the misconception that sufferers from TS will always outgrow related behavioural problems. If these problems are not treated, the possibility exists that these children, when they become adults, will exhibit the same, or other behavioural patterns although these may manifest themselves in different ways, such as physical, sexual, and emotional battering or abusing of their spouses and children. In support of this it can be pointed out that Eldridge $e t$ al. (1977:163) in their study of 21 families where a family member suffered from TS, found that sexual abuse occurred in 12 cases. Comings (1990:263) also describes six cases in which a relationship between TS and child battering could be found. These findings raise questions about genetic 
influences on family violence, and, as Lystad (1986:63) points out, these also need to be explored.

In cases where incidents of child battering occur, it is advisable to have the parents evaluated for TS. Should such an evaluation prove positive for TS (or as is common in adults, a TS variant) it is essential that the batterer should receive psychopharmacotherapy in combination with psychoterapy and behaviour therapy. This also applies in the case of other forms of family violence. Since TS is a genetically inheritable condition that can be treated effectively, early diagnosis and treatment is essential for the prevention, rehabilitation and possibly the breaking of a vicious circle of violence that occurs in many families.

\section{Bibliography}

BORLAND, M. 1976. Violence in the Family. Manchester : Manchester University Press

BORMAN, L.D. 1982. Helping People to Help Themselves: Self-help and Prevention. New York : Haworth.

CHASE, T.N., FRIEDHOFF, A.J. \& COHEN, D.J. 1992. Advances in Neurology. Tourette Syndrome: Genetics, Neurobiology, and Treatment (Vol. 58). New York : Raven.

COLVIN, D. 1982. Violence in the Family: Theory and Practice in Social Work. Edinburgh : Her Majesty's Stationery Office

COMINGS, D.E. 1990. Tourette Syndrome and Human Behavior. Duarte, Calif : Hope Press.

EEKELAAR, J.M. \& Katz, N.K. 1978. Family Violence: An International and Interdisciplinary Study. Toronto : Butterworths.

ELDRIGE, R., SWEET, R., LAKE, R., ZIEGLER, M. \& SHAPIRO, A.K. 1977. Gilles de la Tourette's Syndrome: Clinical, Genetic, Psychologic, and Biochemical Aspects in 21 Selected Families. Neurology, 27:115-124

FINKELHOR, D. 1983. The Dark Side of Families: Current Family Violence Research Beverly Hills, Calif : Sage

GARBARINO, J. \& GARBARINO, A.C. 1982. Maltreatment of Adolescents. Chicago NCPCA Publishing Department

KURLAN, R 1993. Handbook of Tourette's Syndrome and Related Tic and Behavioral Disorders. New York : Marcel Dekker.

LYSTAD, M. 1986. Violence in the Home: Interdisciplinary Perspectives. New York Brunner.

MUlleR, J. 1987. The Soup Kitchen: A Critique of Self-Help. Community Development Journal, 22(1):36-45.

PAGELOW, M. 1981. Children in Violent Families: Direct and Indirect Victims. Paper presented at the Research Conference on Young Children and Their Families, Anaheim, Calif.

STRAUS, M.A., GELLES, R.J. \& STEINMETZ, S.K. 1980. Behind Closed Doors: Violence in the American Family. New York : Anchor.

TESTY KIDS DRIVE PARENTS TO DRINK. (Weekend Post, Port Elizabeth, 1990-09-01).

WALKLATE, S. 1989. Victimology: The Victim and the Criminal Justice Process. London Unwin Hyman. 